\title{
Efficacy of Platelet-rich Plasma vs Corticosteroid Injection in Chronic Plantar Fasciitis: A Comparative Study
}

\author{
Manjeet Singh ${ }^{1}$, Ashwani Ummat ${ }^{2}$, Chetan Sharma ${ }^{3}$, Praveen S Thivari ${ }^{4}$, Sonia Kochhar ${ }^{5}$
}

\begin{abstract}
Introduction: Chronic plantar fasciitis (PF) is the most common cause of foot complaints making up to 11-15\% of the foot symptoms requiring professional care among adults. Also, it is a common problem that affects sport participants as well as inactive middle-aged individuals. The purpose of this study was to compare the effect of steroid and platelet-rich plasma (PRP) in chronic PF. The results were assessed by comparing American orthopedic foot and ankle scale (AOFAS) and visual analogue scale (VAS) before injection, 1, 2, and 6 months after injection in both groups comprising 25 patients in each group.

Results: In our study of 50 patients, in steroid group-A, there is significant change in mean VAS from $6.28 \pm 0.86$ before follow-up injection to $2.8 \pm 0.76$ in first follow-up visit ( 1 month after injection) and to $2.92 \pm 0.75$ in second follow-up visit ( 2 months after 1 st injection) and remained constant at $2.92+0.75$ at third follow-up ( 6 months post 1st injection) and significant change in mean AOFAS from $67 \pm 10$ before injection to $85.76 \pm 5.44$ in first follow-up visit ( 1 month after injection) and to $84.16+5.94$ in second follow-up visit ( 2 months after first injection) and deteriorated further to $83.92+5.84$ at third follow-up ( 6 months after first injection). In 25 patients in group B, there is significant change in mean VAS from $5.8 \pm 80.78$ before follow-up injection to $1.96 \pm 0.45$ in first follow-up visit (1 month after injection) and to $1.96 \pm 0.45$ in second follow-up visit ( 2 months after first injection) and remained constant at $1.96 \pm 0.45$ at third follow-up ( 6 months post first injection) and significant change in AOFAS from $68.44 \pm 17.78$ before injection to $89.56 \pm 0.91$ in first follow-up visit ( 1 month after injection) and to $89.84 \pm 0.55$ in second follow-up visit ( 2 months after first injection) and improved further to $89.92 \pm 0.40$ at third follow-up ( 6 months after first injection).

Conclusion: PRP injection is more effective than corticosteroid injection in the treatment of chronic PF in the long run.

Keywords: Chronic plantar fasciitis, Corticosteroid, Platelet-rich plasma.

Journal of Foot and Ankle Surgery (Asia-Pacific) (2019): 10.5005/jp-journals-10040-1097
\end{abstract}

\section{INTRODUCTION}

Chronic plantar fasciitis is the most common cause of foot complaints, making up $11-15 \%$ of the foot symptoms requiring medical care among adults. ${ }^{1}$

As well, it is a common problem that affects sport participants as well as inactive middle-aged individuals. ${ }^{2}$ The diagnosis is grounded on typical history and the finding of localized tenderness in the middle calcaneal tubercle. ${ }^{3}$ Overpulling and stretching of plantar fascia either from excessive exercise or overuse, recurrent trauma, ageing, obesity, poor fitting foot wear, or poor foot alignment while running or extended standing produce microscopic tears of collagen or cystic degeneration in the origin of plantar fascia causing pain and inflammation. The classic presentation of PF is pain on the sole of foot at the inferior region of the heel which is particularly worse with the first step taken on rising in the morning. Increasing knowledge of the pathology has led to the widespread application of a large number of conservative treatments for recalcitrant PF including physiotherapy, plantar fascia stretching exercises, ice packs, night splints, prefabricated and custom-made insert shoe modification, and nonsteroidal antiinflammatory drugs (NSAIDs). ${ }^{4}$

Local injection modalities are commonly used secondary to conservative therapies in the treatment of patients who have resistant PF. Corticosteroid injections have been used to treat plantar heel pain since the 1950 s. ${ }^{5}$ The advantages of corticosteroid injections include low cost, low complexity, and rapid pain relief. However, many are concerned about the potential complications associated with this treatment modality, which may offset its benefits. PRP, which is a natural concentrate of autologous growth
${ }^{1-5}$ Department of Orthopedics, Maharishi Markandeshwar Institute of Medical Sciences and Research, Ambala, Haryana, India

Corresponding Author: Ashwani Ummat, Department of Orthopedics, Maharishi Markandeshwar Institute of Medical Sciences and Research, Ambala, Haryana, India, Phone: +91 7988652326, e-mail: kochhar. sonia.dr@gmail.com

How to cite this article: Singh M, Ummat A, et al. Efficacy of Plateletrich Plasma vs Corticosteroid Injection in Chronic Plantar Fasciitis: A Comparative Study. J Foot Ankle Surg (Asia-Pacific) 2019;6(1):2-6.

Source of support: Department of Orthopedics, MMIMSR, Ambala, Haryana, India

Conflict of interest: None

factors, is now being widely tested in different fields of medicine for its possibilities in aiding the regeneration of tissue with low healing potential. ${ }^{6}$ In Europe and the United States, there is an increasing prevalence of the use of autologous blood products to facilitate healing in a variety of applications. New data exist about specific growth factors, which play a crucial role in the healing process. With that knowledge, there is abundant enthusiasm in the application of concentrated platelets, which release a supramaximal quantity of these growth factors to stimulate recovery in nonhealing injuries. ${ }^{7}$

Autologous PRP was proved to improve the early neotendon properties and improve tissue healing by enhancing cellular chemotaxis, proliferation and differentiation, removal of tissue debris, angiogenesis, and the laying down of extracellular matrix. Various growth factors released from PRP are shown in Table $1 .{ }^{8}$

() The Author(s). 2019 Open Access This article is distributed under the terms of the Creative Commons Attribution 4.0 International License (https://creativecommons. org/licenses/by-nc/4.0/), which permits unrestricted use, distribution, and non-commercial reproduction in any medium, provided you give appropriate credit to the original author(s) and the source, provide a link to the Creative Commons license, and indicate if changes were made. The Creative Commons Public Domain Dedication waiver (http://creativecommons.org/publicdomain/zero/1.0/) applies to the data made available in this article, unless otherwise stated. 
Table 1: Various growth factors released from PRP

\section{PDGF}

- Stimulates cell replication

- Promotes angiogenesis

- Promotes epithelialization

- Promotes granulation tissue formation

TGF

- Promotes formation of extracellular matrix

- Regulates bone cell metabolism

VEGF

- Promotes angiogenesis

EGF

- Promotes cell differentiation and stimulates

- Reepithelialization, angiogenesis, and collagenase activity

FGF

- Promotes proliferation of endothelial cells and fibroblasts

- Stimulates angiogenesis

Abbreviations: PDGF, platelet-derived growth factor; TGF, transforming growth factor; VEGF, vascular endothelial growth factor; EGF, epidermal growth factor; FGF, fibroblast growth factor

\section{Materials and Methods}

\section{Inclusion Criteria}

Fifty patients who visited our hospital outpatient department (OPD) from 2016 to 2018 were included in our study. All patients gave informed consent to participate in the study. Patients were included if they were above 18 years of age and experienced heel pain felt maximally over the planter aspect for at least 6 months continuously. In patients with bilateral heel pain, right foot was included in our study.

\section{Exclusion Criteria}

Patients not willing to give consent, and diabetic patients and patients with age less than 18 years were excluded in our study.

Patients were randomly divided into two groups, group $A$ to be administered corticosteroid and group $B$ to be administered PRP injection, consisting of 25 patients each.

Patients were given 3 doses of injection, first at date of first visit, second at first month post first injection, and third at 2 months post first injection and were followed up till 6 months post first injection. On each visit, patients were assessed with VAS and AOFAS.

PRP injection was prepared in our blood bank using centrifugation technique after withdrawing $40 \mathrm{~mL}$ blood from antecubital site of the patient. Blood was anticoagulated with citrate phosphate dextrose adenine (CPDA) with a ratio 1:6 to the blood. After ten minutes of centrifugation at 2,000 rpm, the blood got layered in three basic components: red blood cell, platelets, and platelet poor plasma (PPP). Because of the different sediment coefficients, the red blood cells were at the lowest level, platelets were in the middle, and the plasma was at the top. Supernatant, including platelets and plasma, were drawn from the tube, leaving red blood cells at the bottom. This supernatant containing platelets and plasma was put in other tubes and agitated for several seconds. Then it was again centrifuged, but at 2,600 rpm for 10 minutes. After centrifugation, two layers were formed in which the supernatant was PRP while the lower layer was concentrated platelets. About three quarters of the supernatant was discarded, the residual PRP (approximately $4 \mathrm{~mL}$ ) was drawn into a syringe.
Affected foot was exposed and after proper cleaning and draping, the foot was approached through medial site using $20 \mathrm{G}$ disposable steel needle. PRP was injected in the foot with the help of a 10 cc syringe. Needle was removed and aseptic dressing was done. Patient was instructed to flex and extend the ankle several times to allow equal distribution of PRP throughout. Patient was discharged from OPD with advice of cold compresses of foot for 24 hours, full weight bearing, oral antibiotics (tablet levofloxacin $750 \mathrm{mg}$ OD) for three days and not to use analgesics for treatment. Patient was advised to come after one month for next injection, then after 2 months for third injection, and then as per follow-up schedule. Patient was instructed to do regular flexion and extension exercises and not to take any oral analgesic during the period of follow-up.

In case of corticosteroid injection group, affected foot was exposed and after proper cleaning and draping, the foot was approached through medial site using $20 \mathrm{G}$ disposable steel needle. $2 \mathrm{~mL}$ methylprednisolone along with $1 \mathrm{~mL}$ local anaesthetic was injected in the medial aspect of the foot.

Patients were asked to come for follow-up at 0, 1, 2, and 6 month interval. On each follow-up, patients were evaluated again using VAS and ankle-hind foot scale. Adverse effects if any were also recorded.

\section{Results}

In our study, 41-50 years is the age group which got most affected in both corticosteroid (A) [48\%] and PRP injection (B) [40\%] groups. The mean age of the patients in group $A$ was $42.76 \pm 9.38$ years and in group B was $40.40 \pm 9.95$.

In our study, females got more affected than males in both corticosteroid (A) [56\% females] and PRP injection (B) [68\% females] groups. Right side got more affected than left side in both corticosteroid (A) and PRP injection (B) groups.

Mean age of the patients in groups $A$ and $B$ was 42.76 and 40.40 years, respectively. Mean VAS score in groups $A$ and $B$ before injection was 6.08 and 5.88, respectively, which improved to 2.80 and 1.96 , respectively, at one month and deteriorated for group $A$ and improved for group B, 2.92 and 1.96, respectively, at 2 months of follow-up. At the end of 6 months, mean VAS was 2.92 and 1.96, respectively, for groups $A$ and $B$. Mean AOFAS ankle-hindfoot score in groups $A$ and $B$ before injection was 67.00 and 68.44 , respectively, which improved to 85.76 and 89.56 , respectively, at one month of follow-up and deteriorated for group A, 84.14 and improved for group $B, 89.84$. At the end of 6 months, AOFAS ankle-hindfoot score deteriorated further for group $A, 83.92$ and improved further for group B, 89.92.

Statistically significant reduction in heel pain was seen in group B patients, as average VAS score improved from $5.88 \pm 0.86$ at the initiation of treatment to $1.96 \pm 0.45$ at 1 month, $1.96 \pm 0.45$ at 2 months. The improvement was sustained throughout the study; at 6 months, the average VAS score was $1.96 \pm 0.45$. Average AOFAS ankle-hindfoot score improved from $68.44 \pm 17.8$ at the initiation of treatment to $89.56 \pm 0.91$ at one month, $89.84 \pm 0.55$. At the end of 6 months, AOFAS ankle-hindfoot score further improved to $89.92 \pm 0.40$.

In group A patients, after initial improvement in average VAS score at 1-month outcome measure $2.80 \pm 0.76$ from initial VAS score of $6.08 \pm 0.86$, no statistically significant reduction in VAS score was seen throughout the study.

Infact, VAS score increased $2.92 \pm 0.75$ at the end of 2 months, VAS remained constant at $2.92 \pm 0.75$ and did not improve further. 
Table 2: Comparison of VAS at pre injection, one month post injection, 2 months post first injection, and at 6 months post first injection

\begin{tabular}{lllllll}
\hline & & Mean & SD & Median & pvalue & Significance \\
\hline VAS pre injection & Group A & 6.0800 & 0.86217 & 6.00 & $<0.001$ & $\mathrm{HS}$ \\
& Group B & 5.8800 & 0.78102 & 6.00 & & \\
VAS at one month & Group A & 2.8000 & 0.76376 & 3.00 & & \\
\multirow{4}{*}{ VAS at 2 months } & Group B & 1.9600 & 0.45461 & 2.00 & & \\
& Group A & 2.9200 & 0.75939 & 3.00 & & \\
VAS at 6 months & Group B & 1.9600 & 0.45461 & 2.00 & & \\
& Group A & 2.9200 & 0.75939 & 3.00 & & \\
& Group B & 1.9600 & 0.45461 & 2.00 & & \\
\hline
\end{tabular}

Table 3: Comparison of AOFAS at pre injection, one month post injection, 2 months post first injection, and at 6 months post first injection

\begin{tabular}{|c|c|c|c|c|c|c|}
\hline & & Mean & S.D & Median & p value & Significance \\
\hline \multirow[t]{2}{*}{ AOFAS ankle-hindfoot score before injection } & Group A & 67.0000 & 10.00000 & 75.00 & $<0.001$ & $\mathrm{HS}$ \\
\hline & Group B & 68.4400 & 17.78595 & 75.00 & & \\
\hline \multirow[t]{2}{*}{ AOFAS ankle-hindfoot score at one month } & Group A & 85.7600 & 5.44120 & 88.00 & & \\
\hline & Group B & 89.5600 & 0.91652 & 90.00 & & \\
\hline \multirow[t]{2}{*}{ AOFAS ankle-hindfoot score at 2 months } & Group A & 84.1600 & 5.94895 & 88.00 & & \\
\hline & Group B & 89.8400 & 0.55377 & 90.00 & & \\
\hline \multirow[t]{2}{*}{ AOFAS ankle-hindfoot score at 6 months } & Group A & 83.9200 & 5.84466 & 85.00 & & \\
\hline & Group B & 89.9200 & 0.40000 & 90.00 & & \\
\hline
\end{tabular}

Average AOFAS ankle-hindfoot score improved from $67.00 \pm 10.00$ at the initiation of treatment to $85.76 \pm 5.44$ at one month. At the end of 2 months, it started deteriorating to $84.16 \pm 5.94$ and even deteriorated further to $83.92 \pm 5.84$ at the end of 6 months.

The $p$ value for mean VAS scores before the initiation of treatment for both groups was $>0.393$ and at 1 month was $<0.001$, at 2 months $<0.001$, and at 6 months was $<0.001$, which showed a highly significant statistical difference in mean VAS scores throughout the study period between the two study groups (Table 2).

The $p$ value for mean AOFAS ankle-hindfoot scores before the initiation of treatment for both groups was $>0.034$ and at 1 month $<0.001$, at 2 months $<0.001$, and at 6 months was $(<0.001)$, which showed a highly significant statistical difference in mean AOFAS ankle-hindfoot scores throughout the study period between the two study groups (Table 3 ).

\section{Discussion}

This study was designed to compare the efficacy of corticosteroid therapy to PRP therapy for chronic PF. PRP contains a more concentrated amount of platelets than does whole blood. Within platelets are powerful growth factors, including platelet-derived growth factor, transforming growth factor beta, and epidermal growth factor. The injection of PRP into the affected tissue initiates the healing stages necessary to reverse the degenerative process at the base of the plantar fascia. The individual cytokines present in the platelet alpha-granules have been shown to enhance fibroblast migration and proliferation, upregulate vascularisation, and increase collagen deposition in a variety of in vitro and in vivo settings. Additionally, many of these cytokines have been seen to work in a dose-dependent manner. The concentrated growth factors work in a synergetic manner to initiate a tendon healing response. Transforming growth factor b1 is shown to significantly increase type I collagen production by tendon sheath fibroblasts. This same mechanism is likely to be active in chronic PF.

In our patient group, the age range varies between 20 years and 60 years of age. The range of participants age's reflects that there is little doubt that planter fasciitis pain affects the adults specially in middle to later age of life. Females were affected more than males in our study. On the basis of laterality, right side was more affected.

Many authors consider PF a degenerative tissue condition rather than inflammation at the site of origin of the plantar fascia at the medial tuberosity of the calcaneus. Degeneration of collagen occurs at the site of the lesion because of microtears of the fascia that do not heal. The histologic features of chronic PF show no inflammatory cell invasion at the site of the lesion, and the normal fascia and surrounding tissue are replaced by angiofibroblastic hyperplastic tissue. PRP injection delivers platelets with growth factors in high concentrations directly to the site of the lesion, which otherwise is inaccessible to growth factors because of hypovascularity and hypocellularity. The cytokines in platelet alpha granules affect the healing stages necessary to reverse chronic PF by enhancing fibroblast migration and proliferation, increase vascularization, and improve collagen deposition.

Complications related to corticosteroid injection in PF like plantar fascia rupture and infection have been reported in literature. But in our study, we did not encounter any such complications.

Previous studies described PRP injection as an effective treatment option for chronic PF (Table 4).

Our PRP vs steroid comparison matched the results of recent studies as that of Omar et al., who found a significant difference as regards mean VAS between the two groups, favoring the PRP group at 1.5 months follow-up $(p<0.05)$ and also that of Monto who demonstrated that both PRP and steroid groups continued to improve up to 3 months and found that the improvement in the steroid group started to decline after 3 months and was sustained for longer periods in the PRP group. Our results also matched the 
Efficacy of Platelet-rich Plasma vs Corticosteroid Injection

Table 4: Previous studies of PRP treatment in chronic plantar fasciitis

\begin{tabular}{|c|c|c|c|c|c|}
\hline Study & Design & Doses of PRP & Assessment method & Follow-up & Conclusion \\
\hline Shetty et al. ${ }^{9}$ & $\begin{array}{l}\text { Comparison between PRP } \\
\text { injection and corticosteroid } \\
\text { injection ( } 60 \text { patients) }\end{array}$ & 1 & $\begin{array}{l}\text { VAS score FADI AOFAS } \\
\text { score }\end{array}$ & 3 months & $\begin{array}{l}\text { No significant difference } \\
\text { between PRP and } \\
\text { corticosteroid injection }\end{array}$ \\
\hline Monto et al. ${ }^{10}$ & $\begin{array}{l}\text { Comparison between PRP } \\
\text { injection and corticosteroid } \\
\text { injection ( } 50 \text { patients) }\end{array}$ & 1 & AOFAS score & $\begin{array}{l}\text { Preinjection; 3, 6, 12, } \\
24 \text { months }\end{array}$ & $\begin{array}{l}\text { PRP more effective } \\
\text { and durable than } \\
\text { corticosteroid injection }\end{array}$ \\
\hline Kumar et al. ${ }^{11}$ & $\begin{array}{l}\text { PRP injection in } 44 \text { patients } \\
\text { ( } 50 \text { heels) }\end{array}$ & 1 & $\begin{array}{l}\text { VAS score AOFAS } \\
\text { score roles and maud- } \\
\text { sley score }\end{array}$ & 6 months & $\begin{array}{l}\text { PRP injection effective in } \\
\text { treatment }\end{array}$ \\
\hline Aksahin et al. ${ }^{12}$ & $\begin{array}{l}\text { Comparison between PRP } \\
\text { injection and corticosteroid } \\
\text { injection ( } 60 \text { patients) }\end{array}$ & 1 & $\begin{array}{l}\text { VAS score modified } \\
\text { roles and maudsley } \\
\text { score }\end{array}$ & 3 week; 6 months & $\begin{array}{l}\text { PRP injection as effective } \\
\text { as corticosteroid } \\
\text { injection }\end{array}$ \\
\hline Ragab and Othman ${ }^{13}$ & PRP injection in 25 patients & 1 & VAS score ultrasound & $\begin{array}{l}\text { Preinjection; } 2,6 \\
\text { weeks; } 6,12 \text { months }\end{array}$ & $\begin{array}{l}\text { PRP injection effective in } \\
\text { treatment }\end{array}$ \\
\hline Barrett and Erredge ${ }^{14}$ & $\begin{array}{l}\text { Autologous blood injection } \\
\text { in } 9 \text { patients }\end{array}$ & 1 & Ultrasound & $\begin{array}{l}1 \text { week; } 1,2,3,12 \\
\text { months }\end{array}$ & $\begin{array}{l}\text { Autologous blood } \\
\text { treatment effective in } \\
\text { treatment }\end{array}$ \\
\hline
\end{tabular}

Abbreviations: AOFAS, American orthopaedic foot and ankle society; FAAM, foot and ankle ability measure; FADI, foot and ankle disability index; PRP, platelet-rich plasma; SANE, single assessment numeric evaluation; SF-12v2, short form-12 health survey version 2; VAS, visual analog scale

study done by Kumar et al., on efficacy of corticosteroid and PF based on VAS score and at the end of 6 months follow-up our results matched with their results based on VAS score $(p<0.001)$, where PRP results improved at one month significantly and remained constant at the end of 6 months, whereas corticosteroid group VAS score results also improved significantly at one month and deteriorated at the end of 6 months and it also matched their AOFAS scores where scores improved for PRP group constantly at each follow up and declined for steroid group at long interval $(p<0.001)$ (Table 5).

The early improvement with PRP is most probably mediated by the excessive amount of growth factors and cytokines that creates an inflammatory response that subsequently restarts the cycle of tendon repair interrupting the stagnant healing environment. While with steroid injections, it only serves as an antiinflammatory agent that ceases the inflammation early within days and has a negligible effect on regeneration, remodeling, and maturation phase which occurs at a much slower rate compared with the PRP environment rich in growth factors.

PRP was administered at the point of maximum tenderness of the heel. Some studies advocate an ultrasound-guided technique for administering injection in PF. However, Kane et al. reported no significant difference in their comparative study between ultrasound-guided and palpation-guided injection techniques in the management of idiopathic PF. In previous studies, PRP injection was administered with a peppering technique where the fascia was injected at multiple sites through a single skin portal. Other authors used a medial approach to administer PRP. It is not known whether either technique is superior. In the current study, the palpationguided injection technique was used.

Table 5: Comparing the final results of various outcome studies with our study

\begin{tabular}{|c|c|c|c|c|}
\hline References & Score & Baseline score outcomes & Last follow-up score outcomes & Complications \\
\hline Monto et al. ${ }^{10}$ & AOFAS & $\begin{array}{l}\text { PRP group: } 37 \text { (range } 30-56 \text { ), } \\
\text { CCS group: } 52 \text { (range } 24-60 \text { ) }\end{array}$ & $\begin{array}{l}\text { PRP group: } 92 \text { (range 77-100), } \\
\text { CCS group: } 56 \text { (range 30-75) }\end{array}$ & No \\
\hline \multirow[t]{3}{*}{ Kumar et al. ${ }^{11}$} & AOFAS & $60.6 \pm 13.1$ & $81.9 \pm 16.6$ & No \\
\hline & $\mathrm{R}$ and $\mathrm{M}$ & $7.7 \pm 1.4$ & $4.2 \pm 3.2$ & \\
\hline & VAS & 4 (inter-quartile 0.0 ) & 2 (inter-quartile 1.0) & \\
\hline \multirow[t]{4}{*}{ Shetty et al. ${ }^{9}$} & VAS & PRP group $8.1 \pm 1.32$ & PRP group $1.8 \pm 1.12$ & No \\
\hline & & Steroid group $7.8 \pm 1.12$ & Steroid group $4.27 \pm 1.41$ & \\
\hline & AOFAS & PRP group $33.9 \pm 8.15$ & PRP group $83.1 \pm 10.11$ & \\
\hline & & Steroid group $32.5 \pm 7.15$ & Steroid group $70.5 \pm 9.18$ & \\
\hline \multirow[t]{2}{*}{ Omar et al. ${ }^{15}$} & VAS & $\begin{array}{l}\text { PRP group } 8.2 \pm 1.3, \text { CCS } \\
\text { group } 8.8 \pm 0.9\end{array}$ & $\begin{array}{l}\text { PRP group } 2.6 \pm 2.1, \text { CCS } \\
\text { group } 6.5 \pm 2.6\end{array}$ & No \\
\hline & FHSQ & $\begin{array}{l}\text { PRP group } 58.5 \pm 9.6, \mathrm{CCS} \\
\text { group } 57.5 \pm 9.4\end{array}$ & $\begin{array}{l}\text { PRP group } 25.1 \pm 12.4, \mathrm{CCS} \\
\text { group } 49.0 \pm 19.1\end{array}$ & \\
\hline \multirow[t]{5}{*}{ Our study } & VAS & PRP group $5.88 \pm 0.86$ & PRP group $1.96 \pm 0.45$ & No \\
\hline & & Steroid group $6.08 \pm 0.78$ & Steroid group $2.92 \pm 0.75$ & \\
\hline & AOFAS & PRP group $68.44 \pm 17.7$ & PRP group $89.92 \pm 0.40$ & \\
\hline & & Steroid group & Steroid group & \\
\hline & & $67.00 \pm 10.0$ & $83.92 \pm 5.84$ & \\
\hline
\end{tabular}


By this study, we are able to keep PRP therapy more superior than the steroid therapy for long-term benefit in planter fasciitis patients.

\section{Conclusion}

Chronic heel pain is a difficult condition to treat and takes a long time to resolve. Various treatment modalities have been described in literature including surgery. But conservative methods are the treatment of choice; of these, local corticosteroid injections and PRP injections are the treatment of choice these days.

In our study, we concluded that:

- PRP is as effective as corticosteroid injection at achieving symptom relief at one and two months after first injection, for the treatment of $\mathrm{PF}$, but unlike corticosteroid, its effect does not wear off with time. At 6 months follow up after first injection, PRP is significantly more effective than corticosteroid, making it better and more durable than corticosteroid injection. The PRP injection is better for long-term pain relief in planter fasciitis.

- Although there are no complications related to corticosteroids like fat pad atrophy, osteomyelitis of the calcaneus and iatrogenic rupture of the plantar fascia were observed in our study. Considering the complications mentioned in the literature, there is a need for larger sample with long-term follow-up to verify the safety of corticosteroid injection in the treatment of PF.

\section{References}

1. Singh D, Angel J, et al. Fortnightly review. Plantar fasciitis. BMJ 1997 Jul 19;315(7101):172-175. DOI: 10.1136/bmj.315.7101.172.

2. Bolgla LA, Malone TR. Plantar fasciitis and the windlass mechanism: a biomechanical link to clinical practice. J Athl Train 2004 Jan;39(1): 77-82.
3. Barrett SJ, O'Malley R. Plantar fasciitis and other causes of heel pain. Am Fam Phys 1999 Apr 15;59(8):2200-2206.

4. Tahririan MA, Motififard M, et al. Plantar fasciitis. J Res Med Sci 2012 Aug;17(8):799-804.

5. Lapidus PW, Guidotti FP. Local injections of hydrocortisone in 495 orthopedic patients. Ind Med Surg 1957 May;26(5):234-244.

6. Yang $\mathrm{W}, \mathrm{Han} \mathrm{Y}$, et al. Platelet-rich plasma as a treatment for plantar fasciitis. Medicine (Baltimore) 2017 Nov;96(44):e8475. DOI: 10.1097/ MD.0000000000008475.

7. Dhillon RS, Schwarz EM, et al. Platelet-rich plasma therapy-future or trend? Arthritis Res Ther 2012 Aug 8;14(4):219. DOI: 10.1186/ar3914.

8. Cole BJ, Seroyer ST, et al. Platelet-Rich Plasma: Where Are We Now and Where Are We Going? Sport Heal A Multidiscip Approach 2010 May 29;2(3):203-210. DOI: 10.1177/1941738110366385.

9. Shetty VD, Dhillon M, et al. A study to compare the efficacy of corticosteroid therapy with platelet-rich plasma therapy in recalcitrant plantar fasciitis: a preliminary report. Foot Ankle Surg 2014. DOI: 10.1016/j.fas.2013.08.002.

10. Monto RR. Platelet-Rich Plasma Efficacy vs Corticosteroid Injection Treatment for Chronic Severe Plantar Fasciitis. Foot Ankle Int 2014 Apr 13;35(4):313-318. DOI: 10.1177/1071100713519778.

11. Kumar V, Millar T, et al. The treatment of intractable plantar fasciitis with platelet-rich plasma injection. Foot 2013 Jun;23(2-3):74-77. DOI: 10.1016/j.foot.2013.06.002.

12. Akşahin $E$, Doğruyol $D$, et al. The comparison of the effect of corticosteroids and platelet-rich plasma (PRP) for the treatment of plantar fasciitis. Arch Orthop Trauma Surg 2012 Jun 8;132(6):781-785. DOI: 10.1007/s00402-012-1488-5.

13. Ragab EMS, Othman AMA. Platelets rich plasma for treatment of chronic plantar fasciitis. Arch Orthop Trauma Surg 2012 Aug 4;132(8):1065-1070. DOI: 10.1007/s00402-012-1505-8.

14. Stephen LB, Susan EE. Growth Factors for Chronic Plantar Fasciitis? Podiatry Today 2004;17(11):36-42.

15. Omar AS, Ibrahim ME, et al. Local injection of autologous platelet rich plasma and corticosteroid in treatment of lateral epicondylitis and plantar fasciitis: randomized clinical trial. Egypt Rheumatol 2012 Apr 1;34(2):43-49. DOI: 10.1016/j.ejr.2011.12.001. 